\title{
Exploring the Potential of Universal Design for Learning with Regards to Mental Health Issues in Higher Education
}

\author{
Frederic Fovet
}

Royal Roads University

\begin{abstract}
The study explores the potential of Universal Design for Learning (UDL) in addressing mental health $(\mathrm{MH})$ issues within higher education (HE) teaching and learning, from a multidisciplinary perspective. It examines first the hurdles which are generically reported to Accessibility Services by students; it then explores the tension instructors report with regards to addressing students' mental health issues in the classroom. Lastly, the study examines UDL solutions which are being proposed by instructional designers, from a design perspective, to minimize the impact of mental health issues within the learning experience.
\end{abstract}

Context and rationale

This study flows from a presentation which was offered within the Third Pan-Canadian Conference which took place at Royal Roads on October 2nd-4th. The session was created from a multi-disciplinary perspective and was offered by Kyla McLeod, Frederic Fovet and Sophia Palahicky. The aim was to explore (i) how mental health issues in the HE classroom represent a multi-faceted phenomenon, (ii) how specific professional perspectives often only grasp one dimension of this phenomenon, and (iii) how UDL can be useful in providing multidisciplinary, wider scope, design-based, hands-on solutions to tension which is felt around mental health in the classroom. One third of students who currently register with accessibility services in North America do so because they identify as being affected by mental health issues.

Goals of the study

The study explores the potential of Universal Design for Learning (UDL) in addressing mental health issues within higher education (HE)teaching and learning, from a multi-disciplinary perspective. It examines first the hurdles which are generically reported to Accessibility Services by students; it then explores the tension instructors report with regards to addressing students' mental health issues in the classroom. Lastly, the study examines UDL solutions which are being proposed by instructional designers, from a design perspective, to minimize the impact of mental health issues within the learning experience. 


\section{Methodology}

The study uses qualitative methodology to collect data from the various stakeholders. There are three dimensions in the data collection. The researcher first carried out semi-directive interviews of one hour with 5-6 Accessibility Services personnel situated in BC. In these interviews the researcher sought to document the types of hurdles students who are affected by mental health regularly report when it came to teaching and learning. In a second stage of the data collection, the researcher carried out semi-directive interviews with 5-6 HE instructors to explore the tension they reported when it came to addressing mental health issues in the classroom. The researcher examined solutions that were being chosen and hurdles encountered in implementing these solutions. The third part of the data collection focused on instructional designers. Again 5-6 participants were interviewed. This time the focus was to examine mental health issue from a design perspective; the researcher sought to explore with the instructional designers participating whether UDL could assist instructors in eroding the tension which was reported by both students and educators.

The data once collected was transcribed and coded using categories which were extracted from the literature. The appeal of this multi-disciplinary study was to examine the same categories as they were raised by the three groups in different ways; the aim was to then explore how these categories - and the barriers they evoked - overlapped with the UDL literature and the solutions this scholarship proposes. The analysis of the data shows the specific ways UDL can be used to address the concerns most frequently raised around $\mathrm{MH}$ in the classroom by both students (through Accessibility professionals) and instructors. The concrete outcome of the study was to produce specific designed-based and hands-on tips that address realities around $\mathrm{MH}$ issues in the classroom.

Keywords: Universal Design for Learning, Inclusion, mental health, accessibility services, teaching and learning, instructional design 